\title{
Higher Order Thinking Skills to Enhance Millennial Students Through Active Learning Strategies
}

\author{
Ita Fatkhur Romadhoni, Luthfiyah Nurlaela \\ Home Economics Department \\ Universitas Negeri Surabaya \\ Surabaya, Indonesia \\ itaromadhoni@unesa.ac.id
}

\begin{abstract}
This study aims to reveal the application of active learning strategy type student created a case study to improve motivation and learning outcomes. The research subject is a culinary education of home economics students. It was observed by tests, field notes, profile documentation. The analyzes were performed through interactive analysis techniques including data reduction, data presentation, and conclusions. The result shows the number of students with less diligent and tenacious in facing difficulties and duties before the action was held by $10.7 \%$, at the end of the action becomes $71.43 \%$. Students are less brave in answering questions and doing practice questions before the $50 \%$ action takes place, at the end of the action becomes $92.86 \%$. Students are less happy in finding and solving problems before the action is $10.7 \%$, at the end of the action becomes $78.57 \%$. The results of written tests conducted before the action and after the action shows an increase in student learning outcomes. Prior to the result of the students' learning outcomes that get value $>70$ equal to $21,43 \%$ and at the end of action become $78,57 \%$. The conclusion of this research is the implementation of an active learning strategy type student created case study to improve higher order thinking skill was succeed.
\end{abstract}

Keywords-active learning, student-created case study, higher order thinking skills

\section{INTRODUCTION}

The existence of the development of life, education also experienced the dynamics of the longer growing and trying to adapt to the dynamic development movement. That is why the education that is now applied is not the same as the previous education. Every time, there will always be changes that lead to better educational progress [1].

Active learning is needed by students to get maximum learning outcomes. When a student is passive in the learning process, there is a tendency to quickly forget what has been given. Learning that only relies on the sense of hearing has several weaknesses, whereas learning outcomes should be stored for a long time. This fact is in accordance with the wise quotes given by a famous Chinese philosopher Confucius. He said: "What I heard, I forgot. What I see, I remember. What I do, I understand. " [2].

Active learning is one way to tie up new information and store it in the brain. If students are invited to discuss, answer questions or make inquiries, then their brain will work better, so that the learning process can occur well. [3]. concludes ". When students learn actively, it means they dominate the learning activities. They actively use their brains to find key ideas from the subject matter, solve problems or apply what is learned in the real life. "

In a classroom environment, there are various differences in the student circumstances, such as the level of intelligence, courage and student character that will ultimately affect the student's learning outcomes. The consideration of using active learning strategies is the reality that students have different ways of learning. There are students who prefer to read, happy to discuss or happy to practice. This is called learning style. Helping students to the maximum learning and the pleasure in learning is a big responsibility for the teachers. To accommodate those needs, the learning strategies that involve varied learning senses is needed to be used [4]. By using learning strategies, a teacher can teach well. Where a good teaching is not just a transferred knowledge to students, but also about how to help students to learn. [5] explain the definition of a teacher that is closely related to the teacher's obligations?

\section{A. Student create the case study}

A Case study is one of many learning methods that are considered very good. One type of case discussion focuses on the issue of a real case situation or example that requires students to take action, summarize the benefits that can be learned and ways of controlling or avoiding similar situations in the future. The following techniques enable learners to create their own case studies. The steps taken are to form a class into a pair. Invite them to develop a case study and the rest of the class can analyze and discuss. The purpose of the case study is to study the topic by examining real situations or examples that reflect the topic. It allows a sufficient time for each partner or trio to develop a case or issue to discuss or a problem to solve is relevant to the learning material. Then each pair makes a summary of case studies, specific details of events that lead to problem-solving. When the case study is over, the teacher asks the groups to present it into the class. And let them to lead a case discussion.

\section{B. Higher order thinking skills}

High-level thinking occurs when a person takes new information and the information stored in memory and interconnects or rearranges and extends this information to reach a goal or find possible answers in confusing situations. Reminiscent of Bloom's Taxonomy discussed "High-Level Thinking", there are three aspects of the cognitive domain that are part of higher order thinking. [6]. These three aspects are analysis, evaluation and creating. The other three aspects of the 
same realm, namely the aspect of remembering, understanding, and application, fall into the part of the lower-order thinking. [7].

Higher Order Questions (rich questions) are required, questions that require students to conclude, hypothesis, analyze, apply, synthesize, evaluate, compare, contrast or imagine, show high-level answers. In order to answer Higher Order Questions, high logical reasoning is required, high logical thinking is needed by students in the classroom learning process, especially in answering questions, because students need to use their knowledge, understanding, and skills in connecting it into a new situation. [8].

\section{Millenial students}

The millennial generation is the terminology that is currently much discussed. Millennial (also known as Generation Millennial or Generation Y) are demographic (cohort) groups after Generation X. Social researchers often classify the generation born between 1980 - 2000 as the millennial generation. So, it can be said that the millennial generation is a young generation of today who is aged between 15-34 years old [9]. The study of the millennial generation in the world, especially in America, has been widely practiced. Among other studies conducted by the Boston Consulting Group (BCG) with the University of Berkley in 2011 with the theme of American millennial: Deciphering the Enigma Generation. In the previous year, 2010, the Pew Research Center also released a research report entitled millennial: A Portrait of Generation Next. [10].

\section{METHOD}

The research is descriptive research that is collaborative between researcher and teacher as the perpetrator. This study aims to reveal how is the application of active learning strategies type of student creates a case study to improve the ability of high-level thinking. The source of this research consists of primary and secondary files. The primary data is the researcher who performs the actions and the students who receive the action. While the secondary data source in the form of documentation data. The data were collected by observation, interview, and documentation. The data source is the origin of the data obtained or obtained which can be behavior, actions, and notes. The data source in this research is from culinary education student of the home economics State University of Surabaya.

\section{RESULT AND DISCUSSION}

This is evident of the motivation improvement indicators in learning that include the ability of diligent and tenacious students, the ability of students who are happy to find and solve problems, and the ability of students responding/answering questions [11].

Motivation is a conscious effort to influence a person's behavior so that he is moved to act to do something to achieve a certain result or purpose [12]. According to [13].Learning is a change in behavior, where the change leads to the better change, but also there is a possibility of the worse. Changes are not only related to the addition of science but also in the form of skills, skills, attitudes, understandings, self-esteem, interests, temperament, self-adjustment. Motivation and learning are two things that affect each other. According to the authors of motivation to learn is a student attempt to act to do something that aims to change behavior.

TABLE I. RESULTS OF ENHANCING HOTS

\begin{tabular}{|l|l|c|c|}
\hline \multirow{2}{*}{ No } & \multicolumn{3}{|c|}{ Table Column Head } \\
\cline { 2 - 4 } & \multicolumn{1}{|c|}{$\begin{array}{c}\text { High-Level Thinking } \\
\text { Indicators }\end{array}$} & Before & After \\
\hline 1 & persevering and tenacious & $42,86 \%$ & $71,43 \%$ \\
\hline 2 & dare to answer & $50 \%$ & $92,86 \%$ \\
\hline 3 & find and solve problems & $10,7 \%$ & $78,57 \%$ \\
\hline
\end{tabular}

Learning model used in this research is Active Learning Strategy type students create case study According to Ari Samadhi active learning is any form of learning that allows students to play an active role in the learning process itself either in the form of interaction between students and students with teachers in the learning process. Learning Tournament Strategy is one type of active learning strategy. [14] suggests that strategy.

This provides an opportunity for students to be active in groups as a team. Learning Tournament Strategy can lead to a good teamwork and also foster motivation to compete between teams as each team tries to gain the highest point. Students are said to be active when they are happy to find and solve problems by themselves. However, if they are not passive in learning, they will convey their ideas in response to problems from teachers and questions that arise from other students. Students who are happy to find and solve problems from round I to II have significant improvements.

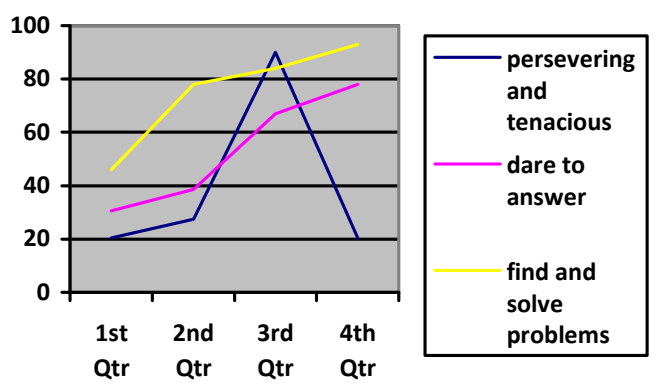

Fig. 1. Higher Thinking Ability

The number of diligent and tenacious students during the study has increased. Prior to the introduction of the type of active learning, students made a case study of the number of diligent and tenacious students as much as 3 students (10.7\%), in the round I to 12 students $(42.86 \%)$, round II increased to as many as 20 students $(71.43 \%)$. According to the act of learning, students are said to be diligent and tenacious if they do not understand. Students who are diligent and tenacious in learning mathematics in the form of rank, roots, and logarithms 
from round I to the second round have increased significantly. The students' willingness and courage are increasing. Before the action, as many as 14 students $(50 \%)$, round I as many as 24 students $(85.71 \%)$, round II as many as 26 students $(92.86 \%)$. Students are willing and courageous if students are willing and courageous both orally and written and willing and courageous when there are other friends who ask questions or answer questions. Students who are willing and courageous from round I to round II experience a significant increase. Students who are happy to find and solve problems also experience improvement. Before the action the number of students who were happy to find and solve the problem only 3 students $(10.7 \%)$, in the first round increased to 14 students $(50 \%)$, the second round was 22 students $(78,57 \%)$. Students are said to be active when happy to find and solve problems if students are not passive in learning, students convey their ideas in response to problems from teachers and questions that arise from other students. Students who are happy to find and solve problems from round I to II have a significant increase [15]

In the learning process, the teacher applies the Active Student learning type student create a case study. Evaluation results can show high and low student learning outcomes. In this study students' results are measured through individual evaluation questions (written tests) provided by the teacher during the study. The learning activities in this classroom study are said to be successful if at least $70 \%$ of the students can achieve the minimum mastery of the test score obtained $>70$. Improved student outcomes are explained from data obtained during two rounds. Students who scored $>70$ before the action as many as 6 students $(21.43 \%)$, round I as many as 18 students $(64.29 \%), 22$ rounds as many as 22 students $(78.57 \%)$. The description shows that after learning mathematics in the form of rank, root, and logarithm through an application of Active Learning Strategy type of student make case study to improve student skills was succeed [16].

\section{CONCLUSION}

Conducting of active learning strategies type students create a case study to improve motivation and student learning outcomes. Improved motivation and student learning outcomes in mathematics learning are shown by the results of research conducted during two rounds. In addition, increased motivation and student learning outcomes are also supported by the opinion of classroom teachers involved in the research. Speech proud thanks to home economics department of the state university of Surabaya which has supported this research.

\section{REFERENCES}

[1] Burr Settles, Mark Craven. An Analysis of Active Learning Strategies for Sequence Labeling Tasks. Proceedings of the 2008 Conference on Empirical Methods in Natural Language Processing, pages 1070 1079,Honolulu October 2008. c 2008 Association for Computational Linguistics

[2] Simon Tong, Daphne Koller. Support Vector Machine Active Learning with Applications to Text Classification. Journal of Machine Learning Research (2001) 45-66.

[3] Freeman S, (2014) Active learning increases student performance in science, engineering, and mathematics. Proc Natl Acad Sci USA 111(23):8410-8415.
[4] Marcia Keyser. Active learning and cooperative learning: understanding the difference and using both styles effectively. Volume 17, Issue 1, Spring 2000, Pages 35-44.

[5] Allen D., Tanner K. (2005). Infusing active learning into the largeenrollment biology class: seven strategies, from the simple to complex. Cell Biol. Educ 4, 262-268.

[6] Maya Patel, Erika Johnson, and Martha Weiss. Active Learning and Student-centered Pedagogy Improve Student Attitudes and Performance in Introductory Biology. CBE-Life Sciences EducationVol. 8, No. 3I.S. Jacobs and C.P. Bean, "Fine particles, thin films and exchange anisotropy," in Magnetism, vol. III, G.T. Rado and H. Suhl, Eds. New York: Academic, 1963, pp. 271-350.

[7] Paul H. Kvam (2012) The Effect of Active Learning Methods on Student Retention in Engineering Statistics, The American Statistician, $54: 2,136-140$

[8] Kimberly S. Scott. An Integrative Framework for Problem-Based Learning and Action Learning

[9] Jochem Verrelst, Sara Dethier, Juan Pablo Rivera, Jordi Munoz-Mari, Gustau Camps-Valls, Jose Moreno, "Active Learning Methods for Efficient Hybrid Biophysical Variable Retrieval", Geoscience and Remote Sensing Letters IEEE, vol. 13, pp. 1012-1016, 2016, ISSN 1545598X.

[10] Swarnajyoti Patra, Kaushal Bhardwaj, Lorenzo Bruzzone, "A SpectralSpatial Multicriteria Active Learning Technique for Hyperspectral Image Classification", Selected Topics in Applied Earth Observations and Remote Sensing IEEE Journal of, vol. 10, pp. 5213-5227, 2017, ISSN 1939-1404

[11] Gina Matasci, Devis Tuia, Mikhail Kanevski, "SVM-Based Boosting of Active Learning Strategies for Efficient Domain Adaptation", Selected Topics in Applied Earth Observations and Remote Sensing IEEE Journal of, vol. 5, pp. 1335-1343, 2012, ISSN 1939-1404.

[12] Changli Li, Lin Zhang, "Hyperspectral image classification by combination of active learning and extended multi-attribute profile", Computer and Communications (ICCC) 2016 2nd IEEE International Conference on, pp. 541-544.

[13] Ana-MariaBliucaPeterGoodyearbRobert A.Ellisc, Research focus and methodological choices in studies into students' experiences of blended learning in higher education.

[14] Wei Di, Melba M. Crawford, "View Generation for Multiview Maximum Disagreement Based Active Learning for Hyperspectral Image Classification", Geoscience and Remote Sensing IEEE Transactions on, vol. 50, pp. 1942-1954, 2012, ISSN 0196-2892.

[15] Katrina A. Meyer, Face-To-Face Versus Threaded Discussions: The Role Of Time And Higher-Order Thinking. JALN Volume 7, Issue 3 September 2003.

[16] D. RandyGarrison, Researching the community of inquiry framework: Review, issues, and future directions Author links open overlay panels. RandyGarrisonaJ.B.Arbaugh. The Internet and Higher EducationVolume 10, Issue 3, 2007, Pages 157-172.

[17] Ana-Maria Bliuc, Peter Goodyear, Robert A. Ellis, Research focus and methodological choices in studies into students' experiences of blended learning in higher education, The Internet and Higher Education, Volume 10, Issue 4, 2007, Pages 231-244, ISSN 1096-7516.

[18] Anat Zohar \& Yehudit J. Dori (2009) Higher Order Thinking Skills and Low-Achieving Students: Are They Mutually Exclusive?, Journal of the Learning Sciences, 12:2, 145-181.

[19] Anat Zohar (2009) The Nature and Development of Teachers Metastrategic Knowledge in the Context of Teaching Higher Order Thinking, Journal of the Learning Sciences, 15:3, 331-377.

[20] Marlene Scardamalia \& Carl Bereiter (2009) Higher Levels of Agency for Children in Knowledge Building: A Challenge for the Design of New Knowledge Media, Journal of the Learning Sciences, 1:1, 37-68. 
[21] Laura Hopkins, Brittany S. Hampton, Jodi F. Abbott, Samantha D. Buery-Joyner, LaTasha B. Craig, John L. Dalrymple, David A. Forstein, Scott C. Graziano, Margaret L. McKenzie, Archana Pradhan, Abigail
Wolf and Sarah M. Page-Ramsey, To the point: medical education, technology, and the millennial learner, American Journal of Obstetrics and Gynecology. 